\title{
An Active Micropump-mixer for Rapid Anti-platelet Drug Screening in Whole Blood
}

Crispin Szydzik $\ddagger^{1,2}$, Rose J. Brazilek $\ddagger^{1}$, Farzan Akbaridoust ${ }^{2,3}$, Charitha de Silva ${ }^{3,4}$, Mitchell Moon ${ }^{1}$, Ivan Marusic $^{3}$, Andrew S. H. Ooi ${ }^{c}$, Harshal H. Nandurkar ${ }^{1}$, Justin R. Hamilton ${ }^{1}$, Arnan Mitchell ${ }^{2}$ \& Warwick S. Nesbitt ${ }^{1,2 *}$

${ }^{1}$ The Australian Centre for Blood Diseases, Monash University, 99 Commercial Road, Melbourne, Victoria, 3004, Australia. ${ }^{2}$ School of Engineering, RMIT University, 124 La Trobe Street, Melbourne, Victoria 3000, Australia.

${ }^{3}$ Department of Mechanical Engineering, Melbourne School of Engineering, The University of Melbourne, Victoria 3010, Australia. ${ }^{4}$ School of Mechanical \& Manufacturing Engineering, The University of New South Wales, Sydney, NSW 2052, Australia. *Dr. Warwick S. Nesbitt. School of Engineering, RMIT University \& The Australian Centre for Blood Diseases, Monash University Alfred Medical Research and Educational Precinct, 99 Commercial Road, Melbourne, Victoria, 3004, Australia.

Email: warwick.nesbitt@rmit.edu.au

\section{TABLE OF CONTENTS}

1. Supplementary Methods

2. Supplementary Figures

3. Legends for Supplementary Videos 


\section{Supporting Information}

\section{SUPPLEMENTARY METHODS}

Device fabrication. Multilayer microfluidic device fabrication was achieved using a combination of a membrane sandwich and onestep PDMS injection molding fabrication methods recently developed within our research group. ${ }^{1-2}$ This fabrication technique greatly simplifies the fabrication of multilayer microfluidic systems, facilitating rapid and highly reproducible fabrication of complex microfluidic structures and actuators with applications to the development of automated blood handling microfluidics. ${ }^{2}$ Briefly, molds were fabricated as two complimentary halves; patterned onto 4 -inch, $500 \mu \mathrm{m}$ thick silicon wafers. SU-8 3050 series photoresist (MicroChem Corp) was used to produce two, and three-layer microfluidic mold structures with a height of 50 and $100 \mu \mathrm{m}$ (collagen channel and primary channel)

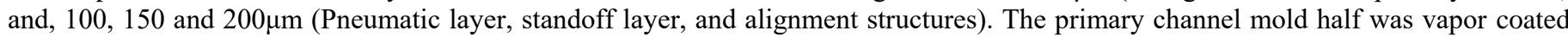
with $1 \mathrm{H}, 1 \mathrm{H}, 2 \mathrm{H}, 2 \mathrm{H}-\mathrm{Perfluorooctyltriethoxysilane} \mathrm{(Sigma} \mathrm{Aldrich)} \mathrm{generating} \mathrm{a} \mathrm{passivated} \mathrm{surface,} \mathrm{facilitating} \mathrm{demolding.} \mathrm{Sylgard} 184$ Silicone Elastomer (Dow Corning) was mixed with curing agent with a weight ratio of 10:1 and degassed under hard vacuum. Degassed pre-polymer was introduced between the molds, which were aligned, clamped and cured for $30 \mathrm{~min}$ at $100^{\circ} \mathrm{C}$. Following curing, molds were separated and the PDMS slab diced and extracted. Interface holes $(0.75 \mathrm{~mm})$ were biopsy punched into a $5 \mathrm{~mm}$ thick blank PDMS interface slab, which was then plasma bonded to the upper surface of the injection molded PDMS slab, sealing and interfacing with top layer structures (Harrick Plasma PDC-002: $100 \% \mathrm{O}_{2}, 1 \mathrm{~min}$ ). Fluidic reservoirs were punched through the bonded layers, followed by plasma bonding with a no. 1 borosilicate coverslip, used to seal the primary channels within the bottom layer. PDMS exclusion stamps were utilized during the final bonding step, as in previous work ${ }^{3}$ to prevent permanent valve gate bonding at bilateral drug gate valves. The entire microfluidic including sample reservoirs was passivated with $10 \% \mathrm{w} / \mathrm{v}$ F127 pluronic block copolymer and $2 \%$ w/v bovine serum albumin (BSA) following derivatization with type 1 collagen.

Platelet $\mathrm{Ca}^{2+}$ assay. Assessment of platelet cytosolic calcium levels $\left[\mathrm{Ca}^{2+}\right]_{\mathrm{c}}$ was adapted from published methods. ${ }^{4-5} \mathrm{Briefly}$, washed platelets $\left(1 \times 10^{9} / \mathrm{mL}\right)$ were loaded with Cal520 (2-aminophenoxy)ethane-N,N,N',N'-tetraacetic acid tetra(acetoxymethyl)ester $(5 \mu \mathrm{M})$ (AAT Bioquest) for $45 \mathrm{~min}$ at $37^{\circ} \mathrm{C}$. Dye-loaded platelets (final platelet count $=200 \times 10^{9} / \mathrm{L}$ ) in Tyrodes $+1 \mathrm{mM} \mathrm{Ca}^{2+} / \mathrm{Mg}^{2+}$ were then reconstituted with washed red blood cells $(40 \% \mathrm{Hct})$ prior to perfusion through the device. Blood perfusion and platelet $\left[\mathrm{Ca}{ }^{2+}\right]_{\mathrm{c}}$ dynamics were acquired on an inverted Nikon TiU microscope (Nikon Plan Fluor 60x/0.50 objective) using an Andor Zyla sCMOS camera at 0.586 frames per second. All image analysis was performed off-line in ImageJ. Images were background corrected and platelet fluorescence thresholded using Huang's fuzzy image thresholding in Image J. ${ }^{6}$ The corrected fluorescence values (F) for each cell were converted into pseudo-ratio values by normalizing for $\mathrm{Ca}^{2+}$ chelated control platelet flows $\left(\mathrm{F}_{\mathrm{min}}\right)$, as described elsewhere. ${ }^{4}$ The pseudo-ratio value was calculated as $\mathrm{F}^{\prime}=\mathrm{F} / \mathrm{F}_{\mathrm{min}}$, where Fmin was derived for independent platelet flow experiments in which Cal520 loaded platelets were treated with $50 \mu \mathrm{M}$ DM-BATPA and resuspended in Tyrodes buffer supplemented with $2 \mathrm{mM} \mathrm{EGTA} / \mathrm{MgCl}_{2}$. $\left[\mathrm{Ca}^{2+}\right]_{\mathrm{c}}$ in $\mathrm{nM}$ was derived according to Equation 1.

$$
\left[\mathrm{Ca}^{2+}\right]_{\mathrm{c}}=\mathrm{K}_{\mathrm{d}} \times \mathrm{F}^{\prime} /\left(\mathrm{F}^{\prime}{ }_{\max }-\mathrm{F}^{\prime}\right)\left[\mathrm{K}_{\mathrm{d}} \mathrm{Cal} 520=320 \mathrm{nM}\right] \text { Eq. } 1
$$

The maximal pseudo-ratio fluorescence F'max was determined for each set of flow conditions following incubation of washed platelets with $2.5 \mu \mathrm{M}$ A23187 in Tyrodes buffer supplemented with $5 \mathrm{mM} \mathrm{CaCl}$. Defined regions of interest were analyzed relative to pump components.

FACS analyses. Prior to perfusion, PDMS devices and microcapillaries were coated with $2 \%$ w/v BSA for 10 minutes, while the PDMS device was also subsequently treated with $10 \% \mathrm{w} / \mathrm{v}$ F127 pluronic block-copolymer for 10 minutes. Whole blood samples in $3.2 \%$ ACD following perfusion through the microfluidic circuit at nominated actuation frequency and pressure mode were collected. Control samples were perfused through a standard $0.1 \mathrm{x} 1 \mathrm{~mm}$ rectangular glass microcapillary tubes (VitroCom Pty Ltd) according to published methods ${ }^{7}$ at shear rates of $4,461,1,454,1,100$, and $361.8 . \mathrm{s}^{-1}$; equivalent to the shear rates generated within the collagen assay segment of the microfluidic system by the micropump-mixer when actuated at $100 \mathrm{kPa} / 6 \mathrm{~Hz}, 50 \mathrm{kPa} / 15 \mathrm{~Hz}, 50 \mathrm{kPa} / 3 \mathrm{~Hz}$, and $25 \mathrm{kPa} / 1 \mathrm{hz}, \mathrm{respectively}$. 5 $\mu \mathrm{L}$ samples from each set of conditions were immediately transferred to $12 \times 75 \mathrm{~mm}$ Falcon ${ }^{\circledR}$ polystyrene test tubes containing, $\alpha-\mathrm{CD} 42 \mathrm{~b}-$ PE, $20 \mu \mathrm{L}$ PAC-1 FITC or $5 \mu \mathrm{L} \alpha-\mathrm{P}$-selectin-FITC. Tubes containing one of each reagent were prepared using inactivated blood as a baseline standard, with tubes containing blood activated with $40 \mu \mathrm{M}$ ADP acting as positive controls. Platelets were identified by light scatter characteristics and confirmed by CD42b expression. Positive controls were used to adjust voltages. To demonstrate specific PAC1 binding a sample containing $10 \mu \mathrm{L}$ RGDS $(10 \mathrm{mg} / \mathrm{mL})$ was included. Acquisition was performed on a BD FACSCalibur (Becton Dickinson) that was routinely calibrated with Calibrite beads in conjunction with FACSComp Version 5.1 software (Becton Dickinson). The results were analyzed with FlowLogic 7.2.1 flow cytometric analysis software.

\section{REFERENCES}

1. Anderson, J. R.; Chiu, D. T.; Jackman, R. J.; Cherniavskaya, O.; McDonald, J. C.; Wu, H.; Whitesides, S. H.; Whitesides, G. M., Fabrication of Topologically Complex Three-Dimensional Microfluidic Systems in PDMS by Rapid Prototyping. Analytical Chemistry 2000, 72 (14), 3158-3164.

2. Szydzik, C.; Niego, B.; Dalzell, G.; Knoerzer, M.; Ball, F.; Nesbitt, W.; Medcalf, R.; Khoshmanesh, K.; Mitchell, A., Fabrication of complex PDMS microfluidic structures and embedded functional substrates by one-step injection moulding. RSC Advances 2016, 6 (91), 87988-87994.

3. Szydzik, C.; Brazilek, R. J.; Khoshmanesh, K.; Akbaridoust, F.; Knoerzer, M.; Thurgood, P.; Muir, I.; Marusic, I.; Nandurkar, H.; Mitchell, A., Elastomeric Microvalve Geometry Affects Haemocompatibility. Lab on a Chip 2018. 


\section{Supporting Information}

4. Heemskerk, J. W.; George, M.; Rook, M. B.; Sage, S. O., Ragged spiking of free calcium in ADP-stimulated human platelets: regulation of puff-like calcium signals in vitro and ex vivo. The Journal of physiology 2001, 535 (3), 625-635.

5. Nesbitt, W. S.; Harper, I. S.; Schoenwaelder, S. M.; Yuan, Y.; Jackson, S. P., A live cell micro-imaging technique to examine platelet calcium signaling dynamics under blood flow. Methods Mol Biol 2012, 788, 73-89.

6. Huang, L.-K.; Wang, M.-J. J., Image thresholding by minimizing the measures of fuzziness. Pattern Recognition 1995, 28 (1), $41-51$.

7. Kulkarni, S.; Nesbitt, W. S.; Dopheide, S. M.; Hughan, S. C.; Harper, I. S.; Jackson, S. P., Techniques to examine platelet adhesive interactions under flow. Methods Mol Biol 2004, 272, 165-86. 


\section{Supplementary Figures}

a.

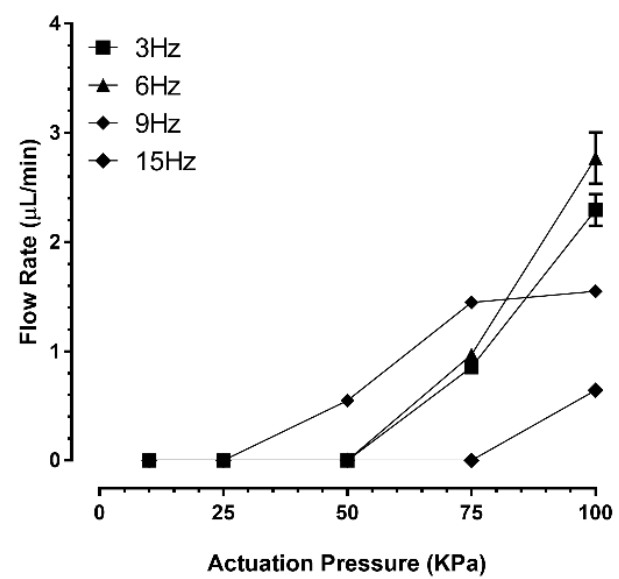

b.

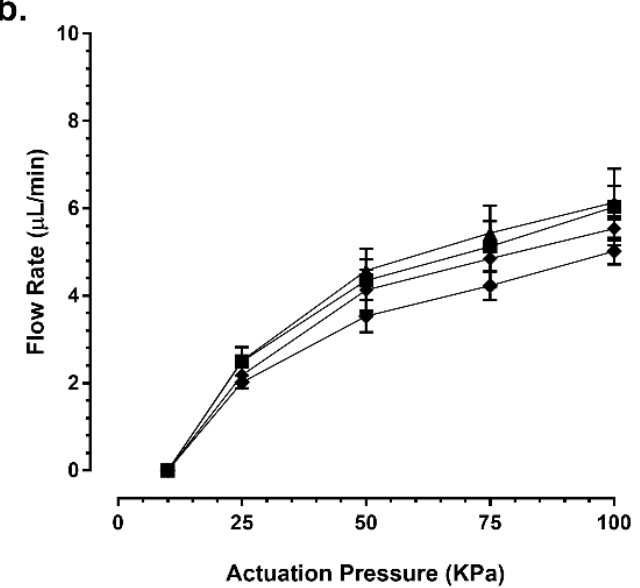

FIGURE S1 a. Flow rate $(\mu \mathrm{L} / \mathrm{min})$ for citrated human whole blood as a function of actuation pressure (kPa) and duty cycle (Hz) for micropump with $0.26 \mathrm{~mm}^{2}$ diaphragm valves. b. Flow rate $(\mu \mathrm{L} / \mathrm{min})$ for citrated human whole blood as a function of actuation pressure $(\mathrm{kPa})$ and duty cycle $(\mathrm{Hz})$ for micropump with $0.41 \mathrm{~mm}^{2}$ diaphragm valves. $\mathrm{n}=3$ independent experiments.

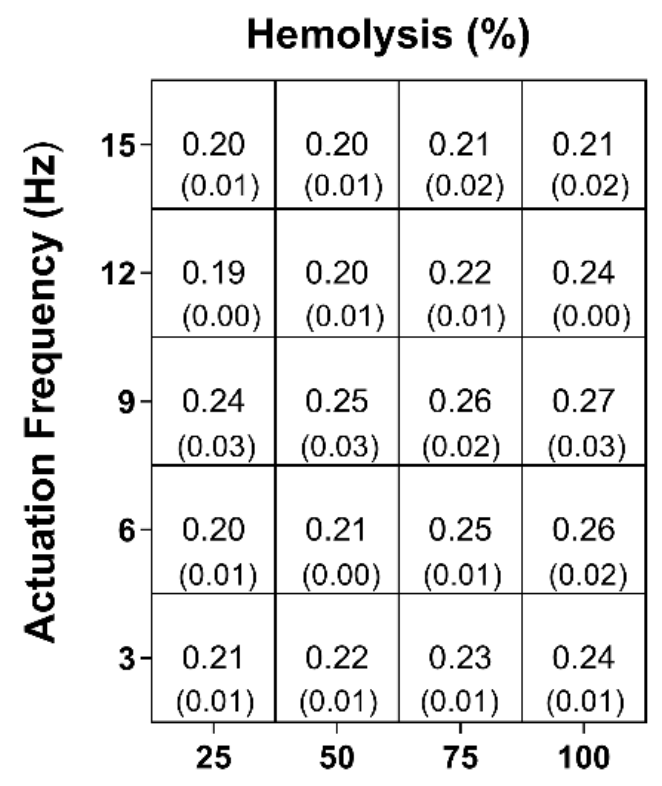

\section{Actuation Pressure (kPa)}

FIGURE S2 \% hemolysis (SD) in human whole blood following perfusion as a function of actuation frequecy (Hz) and pressure (kPa). All data indicates $\mathrm{n}=3$ independent experiments. 
a. $100 \mathrm{kPa} / 6 \mathrm{~Hz}$

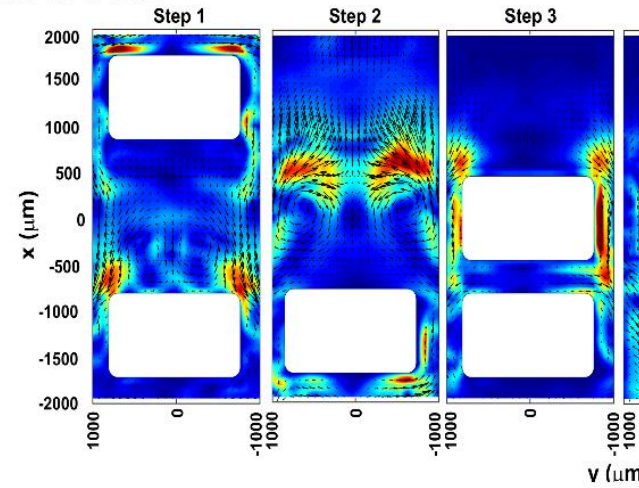

Step 4

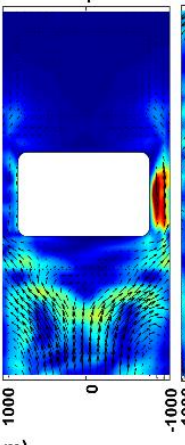

Step 5

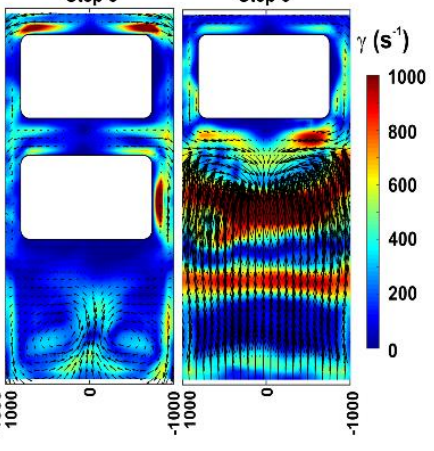

b.

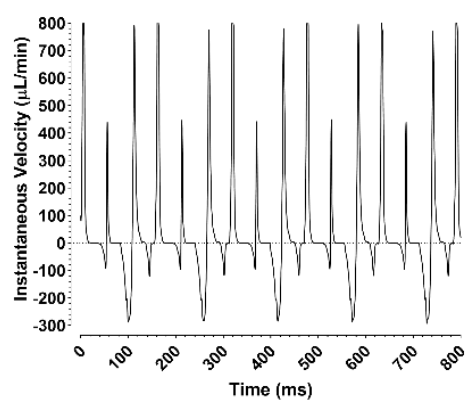

FIGURE S3. $\mu$-PIV assessment of micropump performance

a. $\mu$-PIV contour maps showing planar phase-averaged strain rate magnitude $(\gamma)$ and velocity vectors for micropump operation at $100 \mathrm{kPa} / 6 \mathrm{~Hz}$ (Video S1). Note that panels approximate Steps 1 - 6 of micropump operation. Dotted marques denote opening microvalves; solid marques denote fully closed microvalves. Overall flow direction is bottom-to-top. b. $\mu$-PIV analysis of instantaneous flow rates at cross-section within the downstream collagen assay channel at $100 \mathrm{kPa} / 6 \mathrm{~Hz}$, respectively. Representative of $n=2$ independent experiments for each case.

a.

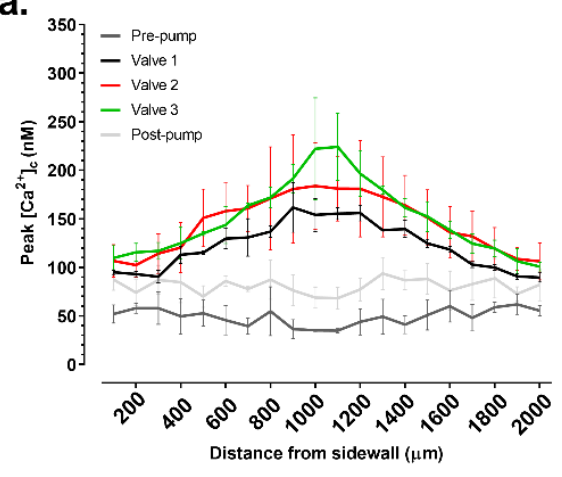

b.

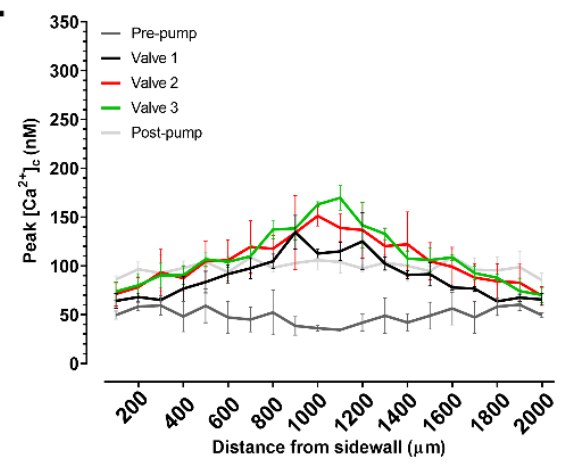

c.

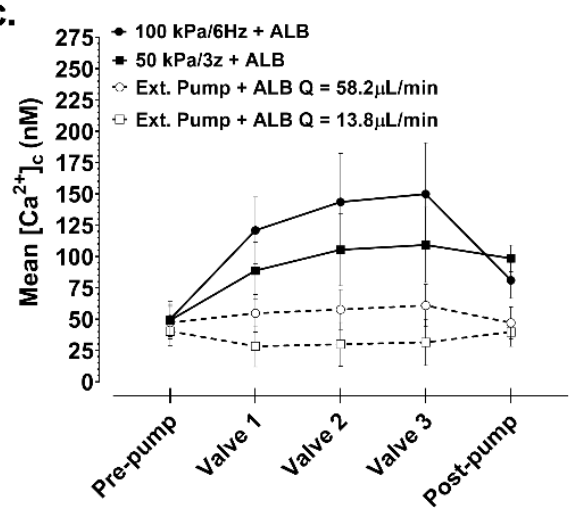

FIGURE S4. Micropump and platelet function with amplification loops blocked

a \& b. Peak platelet $\left[\mathrm{Ca}^{2+}\right]_{\mathrm{c}}$ at $100 \mathrm{k} \mathrm{kPa} / 6 \mathrm{~Hz}$ and $50 \mathrm{k} \mathrm{kPa} / 3 \mathrm{~Hz}$, respectively. Data represents lateral line scans $(100 \mu \mathrm{m}$ bins $)$ at; prepump (2060 $\mu \mathrm{m}$ from V1), valve 1 (apex), valve 2 (apex), valve 3 (apex), post-pump (15.8 mm downstream of V3). c. Mean platelet cytosolic calcium flux $\left[\mathrm{Ca}^{2+}\right]_{\mathrm{c}}$ at $100 \mathrm{kPa} / 6 \mathrm{~Hz}$ and $50 \mathrm{kPa} / 3 \mathrm{~Hz}$ actuation at; pre-pump (2060 $\mu \mathrm{m}$ from V1), valve 1 (apex), valve 2 (apex), valve 3 (apex), post-pump (15.8 mm downstream of V3). ALB : whole blood treated with indomethacin (10 $\mu \mathrm{M})$ (to block $\mathrm{TXA}_{2}$ generation), 2-MeSAMP $(10 \mu \mathrm{M})$ (to block P2Y12-dependent signaling) and MRS2179 (100 $\left.\mu \mathrm{M}\right)$ (to block P2Y1-dependent signaling). $\mathrm{n}=9$ independent experiments. 


\section{Supporting Information}

\section{Supplementary Video Legends}

VIDEO S1. $\mu$-PIV of dynamic micropump operation at $100 \mathrm{kPa} / 6 \mathrm{~Hz}$

$\mu$-PIV analysis showing instantaneous velocity vectors and velocity magnitude $\left(\mathrm{V}_{\mathrm{mag}}-\mathrm{mm} / \mathrm{s}\right)$ of the micropump-mixer operating at 100 $\mathrm{kPa} / 6 \mathrm{~Hz}$. Dotted line and graph (top) show average output flow rate $(\mu \mathrm{L} / \mathrm{min})$ immediately downstream of V3. Video at $0.0075 \mathrm{x}$ normal speed.

VIDEO S2. $\mu$-PIV of dynamic micropump operation at $50 \mathrm{kPa} / 3 \mathrm{~Hz}$

$\mu$-PIV analysis showing instantaneous velocity vectors and velocity magnitude $\left(\mathrm{V}_{\mathrm{mag}}-\mathrm{mm} / \mathrm{s}\right)$ of the micropump-mixer operating at 50 $\mathrm{kPa} / 3 \mathrm{~Hz}$. Dotted line and graph (top) show average output flow rate $(\mu \mathrm{l} / \mathrm{min})$ immediately downstream of $\mathrm{V} 3$. Video at $0.0075 \mathrm{x}$ normal speed.

VIDEO S3. 3D platelet thrombus growth on type 1 collagen in micropump-mixer device

Reconstructed line scanning confocal images of DiOC6 labelled platelet thrombus growth dynamics driven by the micropump-mixer operating at $1 \mathrm{~Hz} / 25 \mathrm{kPa}, 3 \mathrm{~Hz} / 50 \mathrm{kPa}, 6 \mathrm{~Hz} / 100 \mathrm{kPa}$, and $15 \mathrm{~Hz} / 50 \mathrm{kPa}$ respectively. Each frame represents a 30 sec time point scan. 